Article

\title{
Selective Laser Melting of Ti-45Nb Alloy
}

\section{Holger Schwab ${ }^{1, *}$, Konda Gokuldoss Prashanth ${ }^{1, \dagger}$, Lukas Löber ${ }^{1, \star}$, Uta Kühn ${ }^{1}$ and Jürgen Eckert 1,2}

1 IFW Dresden, Institut für Komplexe Materialien, Postfach 270116, D-01171 Dresden, Germany; E-Mails: 1.loeber@ifw-dresden.de (L.L.); u.kuehn@ifw-dresden.de (U.K.); j.eckert@ifw-dresden.de (J.E.)

2 TU Dresden, Institut für Werkstoffwissenschaft, D-01062 Dresden, Germany

$\dagger$ Present Address: R \& D Engineer, Additive manufacturing Center, Sandvik AB, 81181 Sandviken, Sweden; E-Mail: kgprashanth@gmail.com or prashanth.konda_gokuldoss@sandvik.com.

* Present Address: R \& D Engineer, Sauer GmbH-DMG MORI SEIKI, D-87459 Pfronten, Germany.

* Author to whom correspondence should be addressed; E-Mail: h.schwab@ifw-dresden.de; Tel.: +49-351-4659-747; Fax: +49-351-4659-452.

Academic Editor: Hugo F. Lopez

Received: 26 March 2015 / Accepted: 21 April 2015 / Published: 27 April 2015

\begin{abstract}
Ti}-45 \mathrm{Nb}$ is one of the potential alloys that can be applied for biomedical applications as implants due to its low Young's modulus. Ti-45Nb (wt.\%) gas atomized powders were used to produce bulk samples by selective laser melting with three different parameter sets (energy inputs). A $\beta$-phase microstructure consisting of elliptical grains with an enriched edge of titanium was observed by scanning electron microscopy and X-ray diffraction studies. The mechanical properties of these samples were evaluated using hardness and compression tests, which suggested that the strength of the samples increases with increasing energy input within the range considered.
\end{abstract}

Keywords: selective laser melting; Ti-45Nb; additive manufacturing 


\section{Introduction}

Ti-based alloys, Co-based alloys and stainless steels are alloy systems that are widely used as biomedical implants [1]. However, most of these alloys show higher Young's modulus (>70 GPa) compared to the Young's modulus of the cortical bone (10-30 GPa) [2]. These differences cause significant stress shielding [3] due to a mechanical stress mismatch between the implant and the bone, results in loosening of the implant or potential mismatch of the implant in the human body [4,5].

$\beta$-titanium alloys like Ti-45Nb are one of the candidates for such applications because of its low Young's modulus ( $\sim 62 \mathrm{GPa}$ ) due to the presence of the high-temperature bcc $\beta$-phase [6], stabilized by the high niobium content. Also, a high cooling rate will favor the solidification of the bcc $\beta$-phase [7]. This relatively low Young's modulus reduces the risk of the undesired stress shielding effect rendering $\mathrm{Ti}-45 \mathrm{Nb}$ a potential material for biomedical implants [8,9]. In addition, Ti-45Nb possesses excellent ductility [10] and good corrosion resistance [8] apart from the excellent biomedical properties rendered by this alloy. The high affinity of titanium towards oxygen yields a self-generating passive layer consisting of $\mathrm{TiO}_{2}[7,11]$ resulting in superior chemical resistance making it a prominent competitor in the biomedical arena.

Selective Laser Melting (SLM), an additive manufacturing technique developed in the 1980s [12,13], offers the possibility to produce parts with intricate shapes and near net design [14,15] along with high cooling rates resulting in parts with superior properties [15]. Hence, SLM has attracted the attention of both scientific community and industries, where there is a strong demand for the production of novel materials, alloy development and production of near-net shaped materials. SLM involves the production of parts by the interaction of a laser beam selectively with a powder bed [16]. The selective interaction process can be directed from a 3D CAD (Computer Aided Design) model, which gives the processing parameters like the laser power, scanning speed, hatch style etc. layer by layer [16]. The present work focuses on the production of a Ti-45Nb biomedical alloy using the SLM process, followed by structural and microstructural characterization. The mechanical properties of the specimens were evaluated for microhardness and compression tests.

\section{Experimental Section}

\subsection{Powder Fabrication}

$\mathrm{Ti}-\mathrm{Nb}$ rods $(4 \mathrm{~kg}$ ), used to produce powder were commercially acquired from ATI (Albany, NY, USA). Spherical gas atomized powder (GAP) was produced adopting the EIGA method (Electrode Induction-melting Gas Atomization) in an argon (purity 99.999\%) atmosphere, by the company TLS Technik (Bitterfeld-Wolfen, Germany). Wet sieving (fluid: Isopropyl alcohol) was employed to select the powder particles ranging between $20<d<100 \mu \mathrm{m}$. Bulk samples were produced from the GAP using SLM Solutions SLM 250HL device, equipped with a continuous Nd-YAG laser $\left(P_{\max }: 400 \mathrm{~W}\right.$, continuous mode, $\lambda: 1054 \mathrm{~nm}$ and build chamber size: $250 \mathrm{~mm} \times 250 \mathrm{~mm} \times 350 \mathrm{~mm}$ ) with a beam spot size of $\sim 80 \mu \mathrm{m}$. The samples were produced on a Ti-45Nb substrate plate and the building chamber was flooded with high purity argon gas (purity 99.9\%) to avoid oxidation of the samples during the SLM process. To prevent the influx of oxygen from the atmosphere the building chamber was kept under an overpressure of 10 mbar. 


\subsection{Parameter Selection}

Selected combinations of laser powder $P_{\mathrm{L}}$, laser speed $v$, hatch distance along with the energy $E_{\mathrm{V}}$ input employed and the relative density of the samples obtained are shown in Table 1. A strip hatch style with an angle of $74^{\circ}$ was set between the layers to ensure the production of defect free samples. This so called strip or cross hatching avoids the formation of interconnected porosity [17]. A layer thickness of $100 \mu \mathrm{m}$ between layers was used for all experiments.

\subsection{Sample Characterization}

Structural characterization was carried out by X-ray diffraction (XRD) using D3290 PANalytical X'pert PRO (Almelo, The Netherlands) with Co-K $\alpha$ radiation $(\lambda=0.17889 \mathrm{~nm})$ in Bragg-Brentano configuration. Microstructural investigations were carried out by scanning electron microscopy (SEM) in both back scattered and secondary electron modes using Gemini 1530 microscope (Carl Zeiss AG, Oberkochen, Germany) fitted with an energy dispersive X-ray spectrometer (EDX). The density of the samples was evaluated by the Archimedes principle using a Sartorius YDK-01 (0D) device (Sartorius, Göttingen, Germany). Cylindrical samples of $5 \mathrm{~mm}$ diameter and $10 \mathrm{~mm}$ height (DIN 50106) were produced for compression tests and were tested an INSTRON (model 5869) device at a cross head speed of $0.005 \mathrm{~mm} / \mathrm{s}$. The measurements were stopped at a strain of $35 \%$. The hardness was measured with a HMV Shimadzu micro hardness tester with a load of $100 \mathrm{~g}$ for $10 \mathrm{~s}$ on polished samples. Ten indents were performed under each condition and the average value is reported.

Table 1. Selective Laser Melting (SLM) parameters used for building bulk samples and their related densities measured by Archimedes method.

\begin{tabular}{ccccc}
\hline $\boldsymbol{v}[\mathbf{m m} / \mathbf{s}]$ & $\boldsymbol{P}_{\mathbf{L}}[\mathbf{W}]$ & hatching [\%] & $\boldsymbol{E}_{\mathbf{V}}\left[\mathbf{J} / \mathbf{m m}^{\mathbf{3}}\right]$ & rel. density [\%] \\
\hline 35 & 150 & 25 & 137 & $97.7 \pm 1.3$ \\
35 & 250 & 25 & 172 & $99.4 \pm 0.5$ \\
35 & 250 & 50 & 257 & $99.5 \pm 0.2$ \\
\hline
\end{tabular}

\section{Results and Discussion}

\subsection{Ti-45Nb GAP Starting Material}

The GAP used for the present study consists of spherical particles in the range of $20<d<100 \mu \mathrm{m}$ (Figure 1). The powder show the presence of satellites, which may influence the flow ability of the powder (Figure 1) [18]. The XRD pattern (Figure 2) reveals the presence of a single $\beta$-phase (Im-3m), whereas the rod used for gas atomization process consists of two phases (hexagonal $\alpha$-phase and $\beta$-phase). 


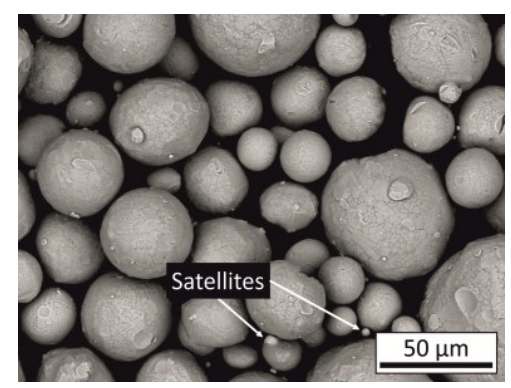

Figure 1. SEM image (Secondary electron mode, $15 \mathrm{kV}$ ) showing the spherical shaped $\mathrm{Ti}-45 \mathrm{Nb}$ gas atomized powder (GAP) particles with the presence of satellites.

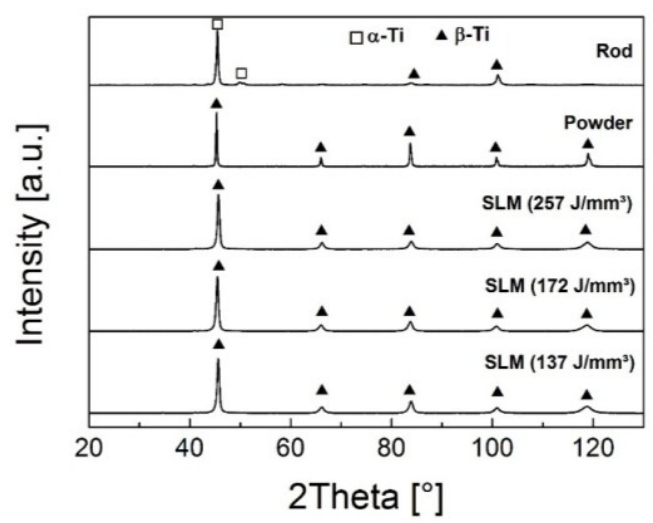

Figure 2. X-ray diffraction patterns of the initial Ti-45Nb rod, the gas atomized powder and of bulk samples produced by SLM with different energy input.

\subsection{Bulk SLM Samples}

The XRD patterns show that all the samples produced by SLM process employ three different parameter sets (see Table 1) that exhibit the presence of single phased $\beta$ structure (space group Im- $3 \mathrm{~m}$ ) (Figure 2), suggesting that the variation in the processing parameters does not have a significant influence on the phase formation in the Ti- $45 \mathrm{Nb}$ alloy. Compared to the XRD patterns of the initial cast rod and the GAP, the SLM samples exhibit broad diffraction peaks. The peak broadening can be a result of the presence of internal stresses in the material and/or a fine grained microstructure $[12,13,15]$.
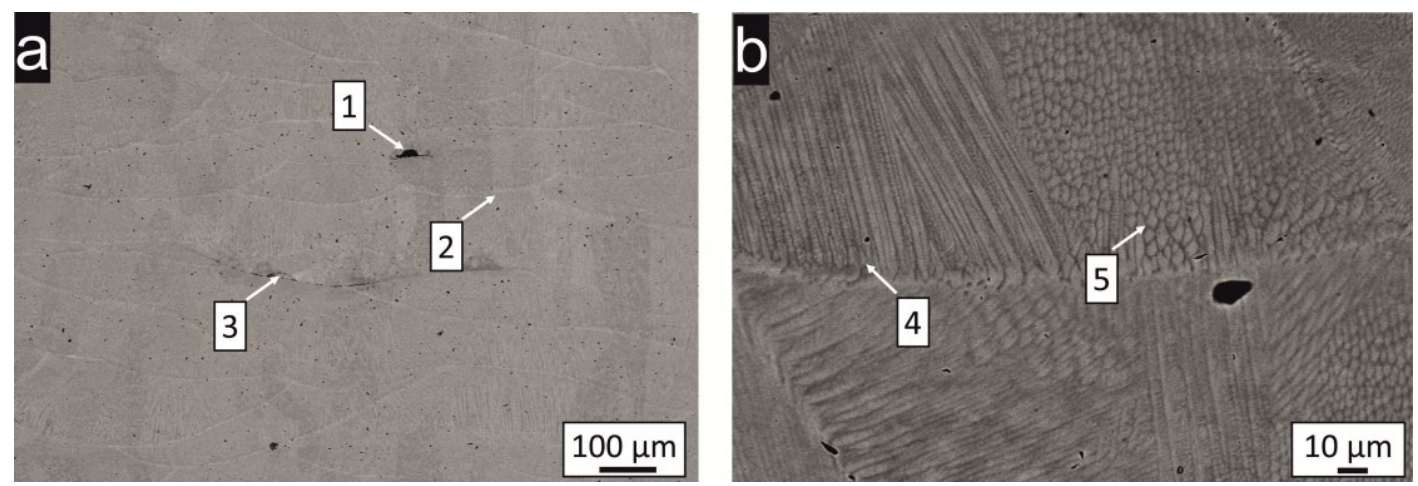

Figure 3. Scanning electron microscopy images of the SLM sample produced with the following parameter set: laser speed, $35 \mathrm{~mm} / \mathrm{s}$; power, $250 \mathrm{~W}$ and hatching overlap, $50 \%$ (Back scattered electron mode, (a) $10 \mathrm{kV}$ (b) $20 \mathrm{kV}$, etchant: Kroll's agent). 


\subsubsection{Microstructure}

The SEM microstructure investigations (Figure $3 \mathrm{a})$ show the presence of pores $(<5 \mu \mathrm{m}$ in diameter) in the material, suggesting that the sample is not completely dense (Table 1). Gas inclusions generated during the melting and re-melting process may result in the formation of spherical porosity in the samples [19]. It can be observed from the longitudinal section of the sample that these pores are distributed all over the samples and they do not have a preferential site. Some irregular pores were also observed, which is characteristic of the additive manufacturing process. Some typical SLM features like the scan track boundaries (2) can also be observed clearly along with the presence of partially molten powder particles (3). The SEM images show that the width of the scan tracks was observed not to be uniform, which might be due to the rotation of the hatches to $74^{\circ}$ between the layers. The solidification process is dominated by an epitaxial growth mechanism (Figure 3) [20]. The solidified layer acts as substrate for the solidifying melt leading to the formation of elliptical-shaped grains orientated perpendicular to the solidification front [20]. The elliptical-shaped grains grow along the same orientation as their neighbors and are separated by thin grain boundaries. Several of these elliptical-shaped grains with same orientation form one cell separated by primary grain boundaries. A similar behavior can also be seen in other materials like AlSi10Mg, Inconel 939 or 316 L [21-24]. The grain growth occurs in a wavelike fashion and the boundary of the elliptical grains are rich in titanium (Figure 4), which is similar to the cellular kind of microstructure observed in Al-12Si alloys, where the cellular boundaries are rich in $\mathrm{Si}$ [15]. The elliptical grains are $\sim 5 \mu \mathrm{m}$ wide and ranges up to $100 \mu \mathrm{m}$ in length.
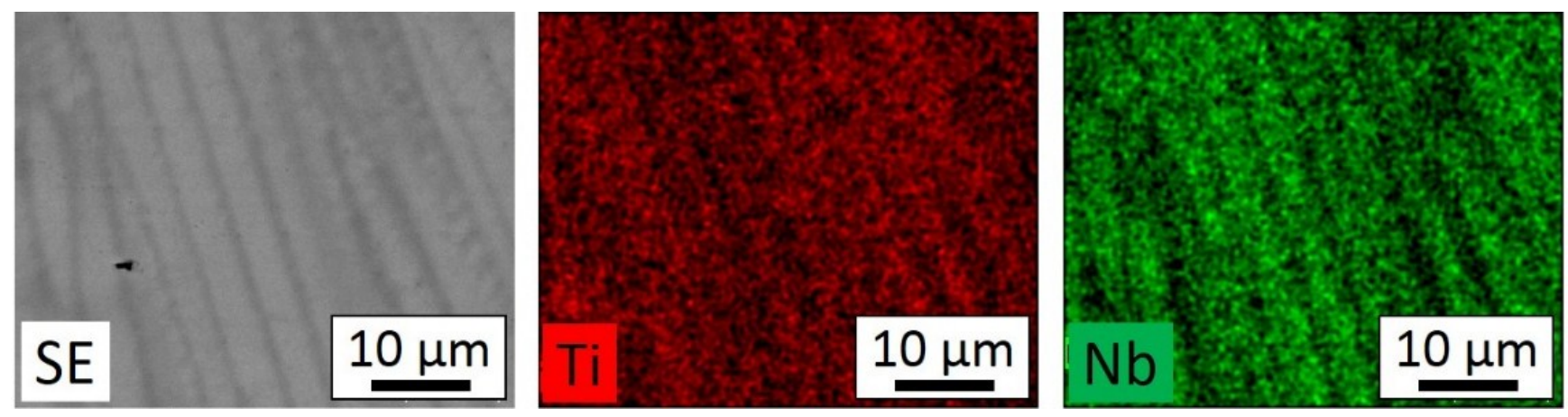

Figure 4. Energy dispersive X-ray spectrometer (EDX) mapping of the elliptical-shaped grains and their segregation edges for samples obtained with the SLM parameters: laser speed, $35 \mathrm{~mm} / \mathrm{s}$ and laser power, $250 \mathrm{~W}$ (etchant: Kroll's agent, $11 \mathrm{kV}$ ).

\subsubsection{Micro Hardness}

The micro hardness data of the SLM samples produced with different parameters is displayed in Figure 5. A micro hardness of $\sim 211 \mathrm{HV}_{0.1}$ is observed for an energy input of $257 \mathrm{~J} / \mathrm{mm}^{3}$ and the value drops to $\sim 192 \mathrm{HV}_{0.1}$ as the energy input is reduced to $137 \mathrm{~J} / \mathrm{mm}^{3}$. The results reveal that the micro hardness is directly correlated with the energy input supplied to the material. With increasing energy input, the thermal gradients change, thereby changing the local heat flux and in turn the cooling rates observed. We expect this to have an influence on the microstructure formation, grain sizes and in turn the hardness (as observed in Figure 5) [20,25-27]. 


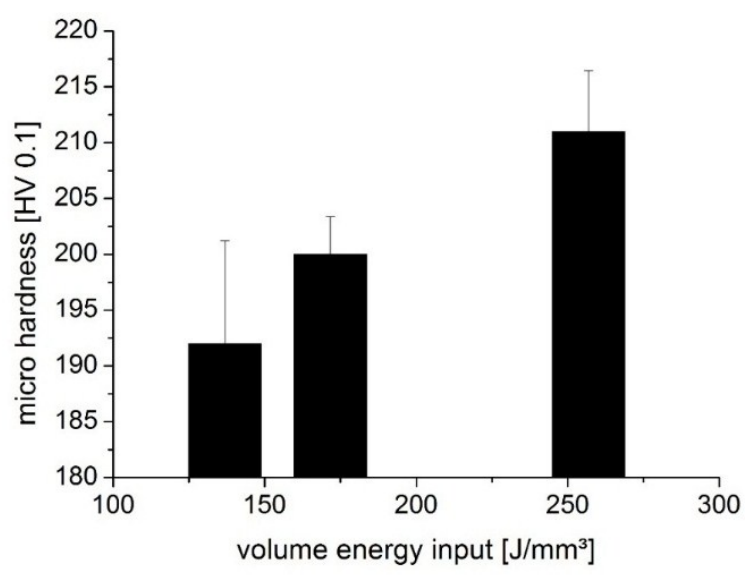

Figure 5. Vickers microhardness data of the samples produced by SLM with different energy input.

\subsubsection{Compression Tests}

Typical room temperature compression test curves are shown in Figure 6. The compression test was stopped at 35\% strain due to technical limitation that may arise from the strain measurement system. It can be observed that the yield strength as well as the compression strength at $35 \%$ increases with increasing energy input and the density of the samples. A highest compressive strength at $35 \%$ strain of $723 \mathrm{MPa}$ is observed for the sample with the highest energy input of $257 \mathrm{~J} / \mathrm{mm}^{3}(99.5 \%$ dense) corroborating the Vickers microhardness results with respect to the increase in strength owing to fine microstructural features observed in the SLM specimens. The strengths of the material under compression do not show a significant variation between the energy densities $137 \mathrm{~J} / \mathrm{mm}^{3}$ and $172 \mathrm{~J} / \mathrm{mm}^{3}$. The compression test results along with the hardness results and density data suggests that the energy input plays a distinct role in creating a fine defect free microstructure and in turn the mechanical properties.

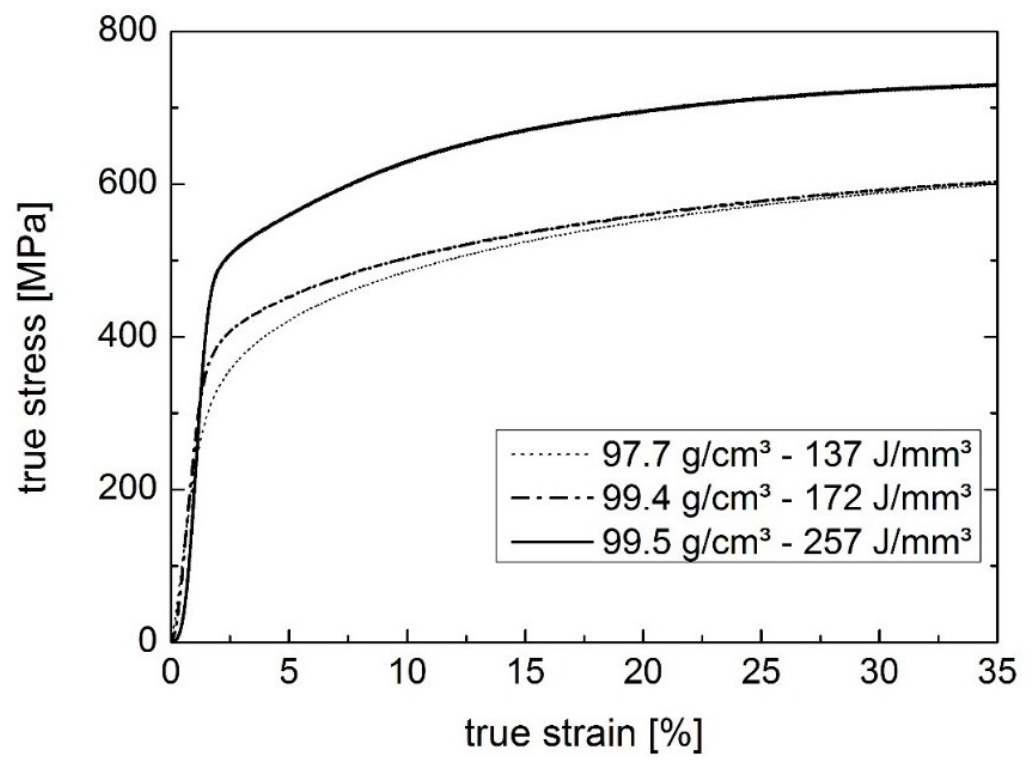

Figure 6. Compression test curves of the samples produced by SLM with different energy input. 
However, the compressive modulus was observed to be $\sim 30-50 \mathrm{GPa}$ higher than the Ti-45Nb alloy prepared by other conventional routes $[6,28,29]$, which might be attributed to the fine microstructure. Thanks to the advantage of such additive manufacturing processes, modification in the modulus can be incorporated in the form of introducing structures in the samples instead of the bulk samples. This suggests that additive manufacturing processes like selective laser melting are suitable for producing custom specific biomaterials.

\section{Conclusions}

Ti-45(wt.\%)Nb samples were successfully produced using the SLM technique with three different parameter sets. The XRD patterns show the presence of $\beta$-phase with broadening of the peaks compared to the GAP, suggesting the presence of internal stresses and/or grain refinement. The SEM images reveal the presence of elliptical grains with $\mathrm{Ti}$ along the boundaries. Both the Vickers micro-hardness as well as the compression test results prove that the strength of the SLM samples increases with increasing energy input.

\section{Author Contributions}

Holger Schwab performed the all experiments and characterization studies and created the initial draft. Konda Gokuldoss Prashanth aided in the preparation of the manuscript and conceived the final manuscript. Lukas Löber helped Holger Schwab with the design of the experiments. Uta Kühn supervised the research and Jürgen Eckert contributed to the overall development of the main concepts of this study.

\section{Conflicts of Interest}

The authors declare no conflict of interest.

\section{References}

1. Epple, M. Biomaterialien und Biomineralisation. Eine Einführung für Naturwissenschaftler, Mediziner und Ingenieure; Springer: Wiesbaden, Germany, 2003.

2. Calin, M.; Helth, A.; Gutierrez Moreno, J.J.; Bönisch, M.; Brackmann, V.; Giebeler, L.; Gemming, T.; Lekka, C.E.; Gebert, A.; Schnettler, R.; et al. Elastic softening of $\beta$-type Ti-Nb alloys by indium (In) additions. J. Mechan. Behav. Biomed. Mater. 2014, 39, 162-174.

3. Niinomi, M.; Nakai, M.; Hieda, J. Development of new metallic alloys for biomedical applications. Acta Biomater. 2012, 8, 3888-3903.

4. Haase, K.; Rouhi, G. Prediction of stress shielding around an orthopedic screw: Using stress and strain energy density as mechanical stimuli. Computers Biol. Med. 2013, 43, 1748-1757.

5. Zhuravleva, K.; Bönisch, M.; Scudino, S.; Calin, M.; Schultz, L.; Eckert, J.; Gebert, A. Phase transformations in ball-milled $\mathrm{Ti}-40 \mathrm{Nb}$ and $\mathrm{Ti}-45 \mathrm{Nb}$ powders upon quenching from the $\beta$-phase region. Powder Technol. 2014, 253, 166-171.

6. Hanada, S.; Matsumoto, H.; Watanabe, S. Mechanical compatibility of titanium implants in hard tissues. Int. Congress Ser. 2005, 1284, 239-247. 
7. Peters, M.; Leyens, C. Titan und Titanlegierungen; Wiley-VCH Verlag GmbH: Weinheim, Germany, 2002.

8. ATI 45 $\mathrm{Nb}^{\mathrm{TM}}$ Alloy, Technical Data Sheet. Available online: https://www.atimetals.com/ Documents/ti-45nb_tds_en_v1.pdf(accessed on 24 April 2015).

9. Gostin, P.F.; Helth, A.; Voss, A.; Sueptitz, R.; Calin, M.; Eckert, J.; Gebert, A. Surface treatment, corrosion behavior, and apatite-forming ability of Ti-45Nb implant alloy. J. Biomed. Mater. Res. 2013, 101B, 269-278.

10. Chen, Y.; Li, J.; Tang, B.; Kou, H.; Zhang, F.; Chang, H.; Zhou, L. Grain boundary character distribution and texture evolution in cold-drawn $\mathrm{Ti}-45 \mathrm{Nb}$ wires. Mater. Lett. 2013, 98, 254-257.

11. Handtrack, D. Herstellung, Gefüge und Eigenschaften Nanokristalliner und Dispersionsverfestigter Titanwerkstoff; Shaker: Aachen, Germany, 2008.

12. Prashanth, K.G.; Shakur Shahabi, H.; Attar, H.; Srivastava, V.C.; Ellendt, N.; Uhlenwinkel, V.; Eckert, J.; Scudino, S. Production of high strength A185Nd8Ni5Co2 alloy by selective laser melting. Addit. Manuf. 2015, 6, 1-5.

13. Kruth, J.-P.; Froyen, L.; van Vaerenbergh, J.; Mercelis, P.; Rombouts, M.; Lauwers, B. Selective laser melting of iron-based powder. J. Mater. Process. Technol. 2004, 149, 616-622.

14. Zhang, B.; Dembinski, L.; Coddet, C. The study of the laser parameters and environment variables effect on mechanical properties of high compact parts elaborated by selective laser melting 3161 powder. Mater. Sci. Eng. A 2013, 584, 21-31.

15. Prashanth, K.G.; Scudino, S.; Klauss, H.J.; Surreddi, K.B.; Löber, L.; Wang, Z.; Chaubey, A.K.; Kühn, U.; Eckert, J. Microstructure and mechanical properties of Al-12Si produced by selective laser melting: Effect of heat treatment. Mater. Sci. Eng. A 2014, 590, 153-160.

16. Löber, L.; Schimansky, F.P.; Kühn, U.; Pyczak, F.; Eckert, J. Selective laser melting of a beta-solidifying TNM-B1 titanium aluminide alloy. J. Mater. Process. Technol. 2014, 214, 1852-1860.

17. Yadroitsev, I.; Smurov, I. Selective laser melting technology: From the single laser melted track stability to 3D parts of complex shape. Phys. Procedia 2010, 5, 551-560.

18. Biamino, S.; Penna, A.; Ackelid, U.; Sabbadini, S.; Tassa, O.; Fino, P.; Pavese, M.; Gennaro, P.; Badini, C. Electron beam melting of Ti-48T1-2Tr-2Tb alloy: Microstructure and mechanical properties investigation. Intermetallics 2011, 19, 776-781.

19. Ardila, L.C.; Garciandia, F.; González-Díaz, J.B.; Álvarez, P.; Echeverria, A.; Petite, M.M.; Deffley, R.; Ochoa, J. Effect of IN718 recycled powder reuse on properties of parts manufactured by means of selective laser melting. Phys. Procedia 2014, 56, 99-107.

20. Yadroitsev, I.; Krakhmalev, P.; Yadroitsava, I.; Johansson, S.; Smurov, I. Energy input effect on morphology and microstructure of selective laser melting single track from metallic powder. J. Mater. Process. Technol. 2013, 213, 606-613.

21. Thijs, L.; Kempen, K.; Kruth, J.-P.; van Humbeeck, J. Fine-structured aluminium products with controllable texture by selective laser melting of pre-alloyed AlSi10Mg powder. Acta Mater. 2013, 61, 1809-1819.

22. $\mathrm{Su}, \mathrm{X}$; Y Yang, Y. Research on track overlapping during selective laser melting of powders. J. Mater. Process. Technol. 2012, 212, 2074-2079. 
23. Kanagarajah, P.; Brenne, F.; Niendorf, T.; Maier, H.J. Inconel 939 processed by selective laser melting: Effect of microstructure and temperature on the mechanical properties under static and cyclic loading. Mater. Sci. Eng. A 2013, 588, 188-195.

24. Ma, P.; Prashanth, K.; Scudino, S.; Jia, Y.; Wang, H.; Zou, C.; Wei, Z.; Eckert, J. Influence of annealing on mechanical properties of Al-20Si processed by selective laser melting. Metals 2014, $4,28-36$.

25. Kruth, J.-P.; Badrossamay, M.; Yasa, E.; Deckers, J.; Thijs, L.; van Humbeeck, J. Part and material properties in selective laser melting of metals. In Proceedings of the 16th International Symposium on Electromachining, Shanghai, China, 19-23 April 2010.

26. Attar, H.; Prashanth, K.G.; Chaubey, A.K.; Calin, M.; Zhang, L.C.; Scudino, S.; Eckert, J. Comparison of wear properties of commercially pure titanium prepared by selective laser melting and casting processes. Mater. Lett. 2015, 142, 38-41.

27. Attar, H.; Calin, M.; Zhang, L.C.; Scudino, S.; Eckert, J. Manufacture by selective laser melting and mechanical behavior of commercially pure titanium. Mater. Sci. Eng. A 2014, 593, 170-177.

28. Ozaki, T.; Matsumoto, H.; Watanabe, S.; Hanada, S. Beta Ti alloys with low Young's modulus. Mater. Trans. 2004, 45, 2776-2779.

29. Hon, Y.-H.; Wang, J.-Y.; Pan, Y.-N. Composition/phase structure and properties of Titanium-Niobium alloys. Mater. Trans. 2003, 44, 2384-2390.

(C) 2015 by the authors; licensee MDPI, Basel, Switzerland. This article is an open access article distributed under the terms and conditions of the Creative Commons Attribution license (http://creativecommons.org/licenses/by/4.0/). 